\title{
LEXICAL. KNOWLEDGE REPRESENTATION IN AN INTELLIGENT DICTIONARY HELP SYSTEM
}

\author{
E. Agirre, X. Arregi, X. Artola, A. Diaz de Ilarraza, K. Sarasola
}

Informatika Fakultatea (Univ, of the Basque Country)

\author{
P. K. 649, 20080 DONOSTI (Basquc Country - Spain) E-mail: jiparzux@si.chu.cs
}

\section{INTRODUCTION.}

IDHS (Intclligent Dictionary Help Systcm) is conceived as a monolingual (explanatory) dictionary systcm for human use (Artola \& Evrard, 92). The fact that it is intended for people instead of automatic processing distinguishes it from other systems dealing with scmantic knowlcdge acquisition from conventional dictionaries. The system provides various access possibilities to the data, allowing to deduce implicit knowledge from the explicit dictionary information. IDHS deals with reasoning mechanisms analogous to those used by humans when they consult a dictionary. Uscr level functionality of the system has been defined and is partially implemented.

The starting point of IDHS is a Dictionary Databasc (DDB) built from an ordinary French diclionary. Meaning definitions have becn analysed using linguistic information from the DDB itself and interpreted to be structured as a Dictionary Knowledge Base (DKB). As a result of the parsing, different lexical-semantic relations between word senses are established by means of semantic rules (atlached to the patterns); this rules are used for the initial construction of the DKB.

This paper describes the knowledge representation model adopted in IDHS to represent the texical knowledge acquired from the source dictionary. Once the acquisition process has been performed and the DKB built, some enrichment processes have been exccuted on the DKB in order to enhance its knowledge about the words in the language. Besides, the dynamic exploitation of this knowledge is made possible by means of specially conceived deduction mechanisms. Both the enrichment processes and the dynamic deduction mechanisms are bascd on the cxploitation of the properties of the lexical scmantic relations represented in the DKB.

In the following section an overvicw of IDIIS is given. Section 3 briefly presents the process of construction of the DKB. The knowledge represcutation model and the enrichment mechanisms are fully described in sections 4 and 5 . Section 6 describes some inferential aspects of the system. [Finally, in section 7, some figures about the size of the prototype built are presented.

\section{THE IDIS DICTIONARY SYSTEM.}

IDIS is a dictionary help system intended to assist a human user in language comprehension or production tasks. The system provides a sct of functions that have been inspired by the different reasoning processes a human user performs when consulting a conventional dictionary, such as definition queries, search of alternative definitions, differences, relations and analogies between concepts, thesaurus-like word scarch, verification of concept propertics and interconceptual relationships, ctc. (Arregi et al., 91).

IDIIS can be scen as a repository of dictionary knowledge apt to be accessed and exploited in several ways. The system has becn implemented on a symbolic architecture machine using KEE knowledge cngincering cnvironment.

Two phases are distinguished in the construction of the DKB. Firstly, infornation contained in the DDB is used to produce an initial DKB. Gencral information about the entries obtained from the DDB (POS, usage, cxamples, etc.) is conventionally represented -attribute-value pairs in the frame structure- while the scmantic component of the dictionary, i.c. the definition sentences, has been analysed and represented as an interrelated set of concepts. In this stage the relations established between concepts could still be, in some cascs, of lexical-syntactic nature. In a sccond phase, the scmantic knowledge acquisition process is completed using for that the relations cstablished in the initial DKB. The purpose of this phase is to perform lexical and syntactical disambiguation, showing that semantic knowledge about hicrarchical relations between concepts can be detcrminant for this.

\section{BUILDING THE DICTIONARY KNOWLEDGE BASE.}

The starting point of this system is a small monolingual Frcnch dictionary (Le Plus Petit Larousse, Paris: Librairic Larousse, 1980) consisting of nearly 23,000 senses related to almost 16,000 cntries. The dictionary was recorded in a relational databasc: the Dictionary Databasc (DDB). This DDB is the basis of every empirical study that has been developed in order to design the final model proposed for representation and intelligent exploitation of the dictionary.

The definition sentences have been analysed in the process of transformation of the data contained in the DDB to produce the DKB. The analysis mechanism used is bascd on hicrarchies of phrasal patterns (Alshawi, 89). The scmantic structure associated to each analysis pattern is expressed by means of a Scmantic Structure Construction Rule (SSCR). The 
process of construction of the DKB is automatic and based on these SSCR's (Aitola, 93).

The interconceptual lexical-semantic relations detected from the analysis of the source dictionary are classificd into paradigmatic and syntagmatic. Nonong the paradigmatic relations, the following tave been found: synonymy and antonymy, taxonomic relations as hypernymy/hyponymy - obtained from definitions of type "genus et differentia"-, and taxonymy itsclf (cxpressed by meins of specific relators such as sorte de and espece de), meronymy, and others as gradation (for adjectives and verbs), cquivalence (between arljectives and past participle), fictitive and relkexive (for verbs), lack and reference (to the previous sense). Whereas among the synlagmatic relations, i.c. those that relate concepts belonging o different I'OS's, derivation is the most important, but also relationships between concepts without any morphological relation als case relations, altributive (for verbs), lack and confomity have been detected.

The hicarchies created have already been used to parse all the noun, yerb, and adjective definitions in the JDDB. The licarchy devoted to analyo noun definitions is fonned with 65 patterns, 49 different patterns have been delined to analyze verb clelinitions, and 45 for adjectives. Although it is a partial parsing, procedure, $57.76 \%$ of noum definitions, $79.8 \%$ of verbs and $69.04 \%$ of those corresponding to adjectives have been tolally "caught" in this application. Ilowever, with this technique of partial parsing, the parse is considered successful when an initial phrase structure is recognized, which in general contans the genus or superordinate of the defined scnse. This is not so for the case of lexicographic mota-language constndions (specitic relators), whose corresponding scmantic structure is built in a specific way and which deserve also specific pattens in the hicratchics.

\section{REIRESLNTATION OF THE DICTIONARY KNOWLEDGK: THE' DKAB.}

As we have just secn, the knowledge representation scheme chosen for the DKB of IDLIS' is composed of thee elements, each of them stituctured as a different knowledge base:

- KB-THISSAURUS is the represcntation of the dictionary as a semantic network of frames, where cach frame represents a one-word concept (word sense) or a phrasal concepl. Phrasal concepts represent phrase structures associated to the occurrence of concepts in matuing definitions. Francs … of units-.. ate interrelated by slots representing lexical-scmantic relations such as synonymy, taxononic relations (hypernymy, hyponymy, and taxonymy itsclo), meronymic relations (part-of, clement-of, sel-of, nember-of), specitic relations realised by means of melalinguistic relators, castats, ctc. Other slots contain phrasal, meta-linguistic, and gencral inlormation.

- KB-DICTIONARY allows access from the dictionary word level to the corresponding concept level in the DKB. Units in this knowledge base represent the cntries (words) of the dictionaty and ate directly linked to their corresponding senses in KB-TIIESAURUS.

- KB-STRUCTURES contains meta-knowledge about concepts and relations in KB-DIC'TIONARY and KB-THESAURUS: all the different structures in the DKB are defined here specifying the corresponding slots and describing the slots by means of lacets that specify their value ranges, inheritance modes, etc. Units in KB-TIIESAURUS and $\mathrm{KB}-\mathrm{I}$ ICTION $\triangle \mathrm{RY}$ are subclasses or instances of classes defincd in KB-STRUCTURES.

Fig. I gives a partial vicw of the three knowledge bases which form the DKB with their correspondent units and their inter/intra relationships.

In the KB-lIIISAURUS, some of the links representing lexical-semantic relations are created when building the initial version of the knowledge basc, while others atre deduced later by means of specially conceived deduction mechanisms.

When a dictionary cutry like spatule $Y$ I: sorte de cuiller plate (a kind of llat spoon) is treated, new concept units are created in KB-TILSSAURUS (and subsidiatily in KB-DICIIONARY) and linked to olhers previously included in it. Doe to the effect of these links new values for some properties are propagated through the resulling laxonomy.

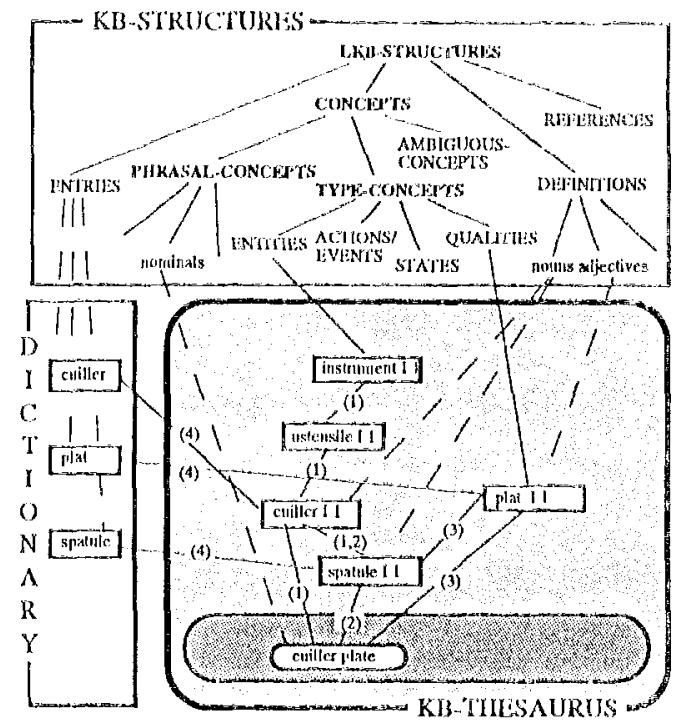

Fig. 1.- The Dictionary Knowledge Base.

-..-SUBCL,Assi link

- . MEMHI:R-OF link (instance)

(1) Tuxonomic Relation: IIYPIIRNYMAYYIONYM

(2) Specitic (uncta-linguistic) relitiom: SORTI-IDI: SOKHI-DH:INV $(\mathrm{XIND}-() \mathrm{H} / \mathrm{KINI})-\mathrm{OF}+\mathrm{INV})$

(3) CARACTLRISTLUU: /CAKAC TERISTYUULE+INY

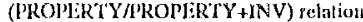

(4) MOTS-LNIKIE ISENS (INTRY WOKU / WORL-GFNSE) relation

In the example, although it is not explicit in thes definition, spatule is "a kind of" ustensile aud so it will inherit some of its chatacteristics (depending upon the inlueritance role of cach attribute). Mig. 1 also shows the types of concepts used: spatule $\gamma I$ and cuiller $I I$ 
ate noun definitions and considered subclasses of LNTITHSS while plat $I$ I (an aljective) is a subclass of QUALITIES. The phrasal concept unit representing the noun phrase cuiller plate is treated as a hyponym of its nuclear concept (cuiller / I).

\subsection{KI3-STIRUCTURES: the meta-knowledge.}

This knowledge basc reflects the hicrarchical organisation of the knowledge included in the DKB.

We will focus on the LKIB-STRUCTURES class which delines the data types used in KBDICTIONARY and KB-TIIESAURUS, and that organises the units belonging to these knowledge bases into a taxonomy.

Slots delined in KB-STRUCTURISS have associated aspects such as the value class, the inheritance role determining how values in children's slots are calculated, and so on. Each lexical-scmantic relation - represented by an attribute or slot- has its own inheritance role. For instance, the inheritance role of the CARACIIRISTIQUI: relation states that every concept inherits the union of the values of the hypernyms for that relation, while the role defined for the SYNONYMLS relation inhibits value inheritance from a concept to its hyponyms.

The subclasses defined under L.KB-STRUCIURYS are the following:

- ENTRIISS, that groups dictionary cntrics belonging to KI\}-DICTIONARY;

- DIFINITIONS, that groups word senses classilied according to their POS;

- RIEIERENCES, concepts created in KBTHIISAURUS due to their occurrence in definitions of other concepts ("definitionless");

- CONCEPTS, that groups, under a conceptual point of vicw, word senses and other conceptual units of KB-THIESAURUS.

Ihe classilication of conceptual units under this last class is as follows:

- TYPL-CONCEP'TS correspond to Quillian's (1968) "type nodes"; this class is, in lact, like a superclass under which every concept of $\mathrm{KB}$ TIIES AURUS is placed. It is further subdivided in the classes ENTTTIES, ACTIONS/EVIENTS, QUALITHES and STATLS, that classify different types of concepts.

- PIIRASAL.CONCEP'TS is a class that includes concepts similar to Quillian's "tokens" -ocentrences of type concepts in the detinition sentences-.. Phrasal concepts are the representation of phrase structures which are composed by several concepts with scmantic content. $\lambda$ phrasal concept is always built as a subclass of the class which represents its head (the noun of a noun phrase, the verb of a verb phrase, and so on), and integrated in the conceptual taxonomy. Phrasal concepts are classified into NOMINALS, VERBALS, ADIECTIVALS, and ADVERBIALS.
For instance, Iplante I $1 \$ 3 \mid$ is a phrasal concent (sce lig. 2), subclass of the type concept Iplante I 1l, and represcnts the noun phrase "une plante d'ornement".

- Finally, the concepts that, after the analysis phase, are not yet completely disambiguated (lexical ambiguity), are placed under the class AMBIGUOUS-CONCEPTS, which is further subdivided into the subclasses IOMOGR APIIE (c.g. Ifaculte ? ?l), SENSE (lpanser I ?l), and COMPLIEX (ldonner I S/6l), in order to distinguish them according to the level of ambiguity they present.

The links between units in KB-TIIESAURUS and KB-J)ICTIONARY are implemented by means of slots tagged with the name of the link they represent. These slots are defined in the different classes of $\mathrm{KB}$ STRUCIURES.

The representation model used in the system is made up of two levels:

- Definitory level, where the surface represcntation of the definition of each sense is made. Morphosyntactic fcatures like verb mode, timc, determination, etc. ate represented by means of facets attached to the attributes. The definitory level is implenconted using representational attributes. Examples of this kind of attributes are: DIFSORTLD, D E F-QUI, CARACTERISTIQUE and AVLC.

- Relational level, that reflects the relational vicw of the lexicon. It supports the deductive behaviour of the system and is made up by means of relational attributes, that may eventually contain deduced knowledge. These attributes, defined in the class IYYPE-CONCEP'TS, are the implementation of the interconceptual relations: ANTONYMES, AGENT, CARACTIRISTIQUE:, SORTY-DI, CE-QUI, ctc.

\subsection{KB-DIC'TIONARY: from words to concepts.}

This knowledge base represents the links between cach dictionary entry and its senses (sec link 4 in Fig. 1).

\subsection{KIB-TIIESAURUS: the concept network.}

KB-TIIES AURUS stores the concept network that is implemented as a network of frames. Each node in the net is a frame that represents a conceptual unit: oneword concepts and phrasal concepts.

The ares interconnect the concepts and represent lexical-semantic relations; they are implemented by means of frame slots containing pointers to other concepts. Hypernym and hyponym relations have been made explicit, making up a concept taxonomy. These laxonomic relations lave been implemented using the environment hicrarchical relationship, in order to get inheritance automatically.

Let us show an example. The representation of the following definition

géranium I 1: une plante d'ornement 
reguires the creation of two new conceptual units in THIESAURUS: the one which corresponds to the delinicndum and the platasal concept which represcuts the noun phase of the delinition. Moreover, the units which represent plante and ornement are to be crealed also (if they have not been previously created because their occurrence in another definition).

lec us suppose that three new units are created: Igéranium I 11, Iplante I $1 \mathrm{H3l}$ and lonencent I 11.

Atributes in the mits may contain facets (attributes for the attributes) used in the definitory level to record aspects like detcomination, gente and so on, but also to establish the relations between delinitory altributes with their contesponding relational, or to specify the certainty that the value in at representational attribute las to be "promoted" to a corresponding relational (sec below the case of the slot DE: in fplante I 1 \$3).

Following is given the compesition of the frames of these three units at the definitory level of representation (slots anc in snall capitats whereas facet identiticrs are in italics):

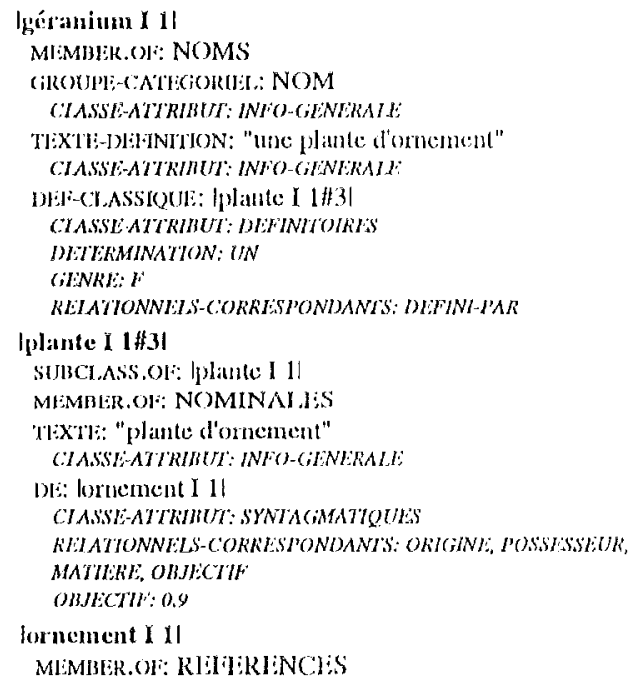

Before showing the representation of these units at the relational level, it has to be said that ater the initial DKB has been built some dednctive procedures have been exceuted: c.g. deduction of inverse telationslips, laxonomy formation, efc. It is 10 sity that in Iig. 2, where the relational view is presented, the relations deduced by these procedures are also represented.

The conceptual units in THISSAURUS are placed in two layers (sce lijg. 2), recalling the two planes of Quillian. The upper layer corresponds to type concepts whereas in the lower phrasal concepts are placed. Every phrasal concept is placed in the taxonomy directly depending from its nuclear concept, as a hyponym of it.

It is interesting to notice in the figure the relation of conceptual equivalence established between Igcranium I II and lphante I 1\#3| (link labelled (3)). These units represent, in fact, the same concept because |plante I 1/H3, standing lo "une plante d'omement", is the defintion of lgeraminn 111.

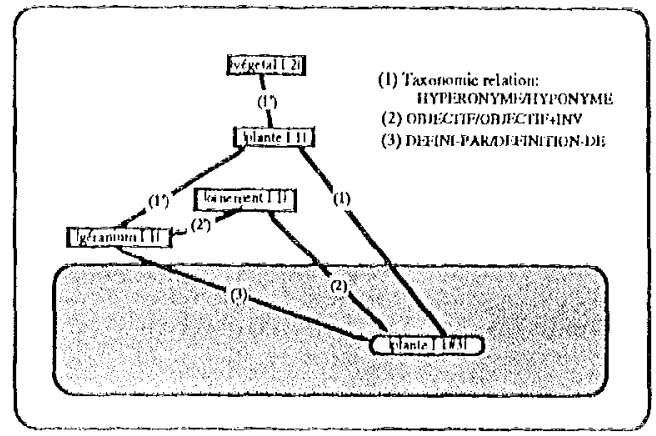

ligg. 2. Relational vicw of the concept lgeranimm I II (in the TIIISAULUSS net).

The frame of fgeranium I II at the relational level of representation lakes the following aspect, once the relational attributes have been (partially) completed:

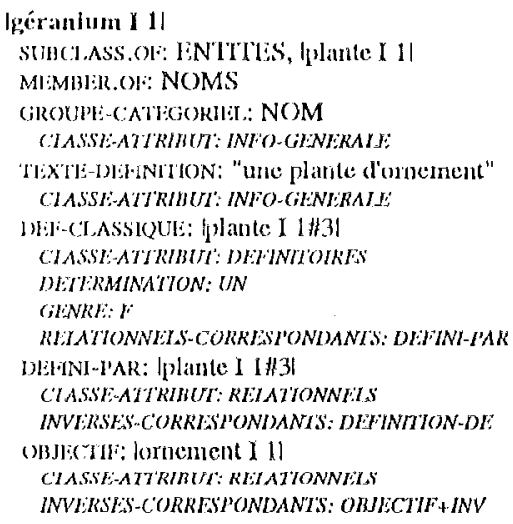

Let us show now another exanple. It is the case of two definitions stated by means of two different stereotyped formulac belonging to the lexicographic mela-language. Mauy verbs in the I,PIJ. are defined by means of a formula beginning with "rendre" and matny nouns with one beginning with "qui". The delinitions selected for this example correspond to the cottics publier $I I$ and ajusterer I 1 , which are represented at the definitory level using the metalanguage attributes DEI-RINNDRI: and DER-QUI respectively:

publier I 1: rendre public

ajusteur I 1: qui ajuste des pièces de métal

The frame corresponding to Ipublier 11 is the lollowing:

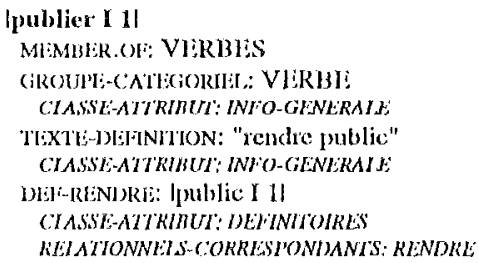

where it cam be secn that no phrasal concept is involved because the link (DER-RENIDRI) is established direculy betwecn fpublice I 11 and 
Ipublic I 11. However, in the case of the definition of ajusteur I $I$, two phrasal concepts are created: the attribute DEF-QUI points to the phrasal concept lajuster I 1 111, representing "ajuster des pièces de métal", and this phrasal concept, in turn, has a syntagmatic attributc (OBJEI) pointing to a nominal that represents "pièce de métal". I ct us show the frames involved in this last casc:

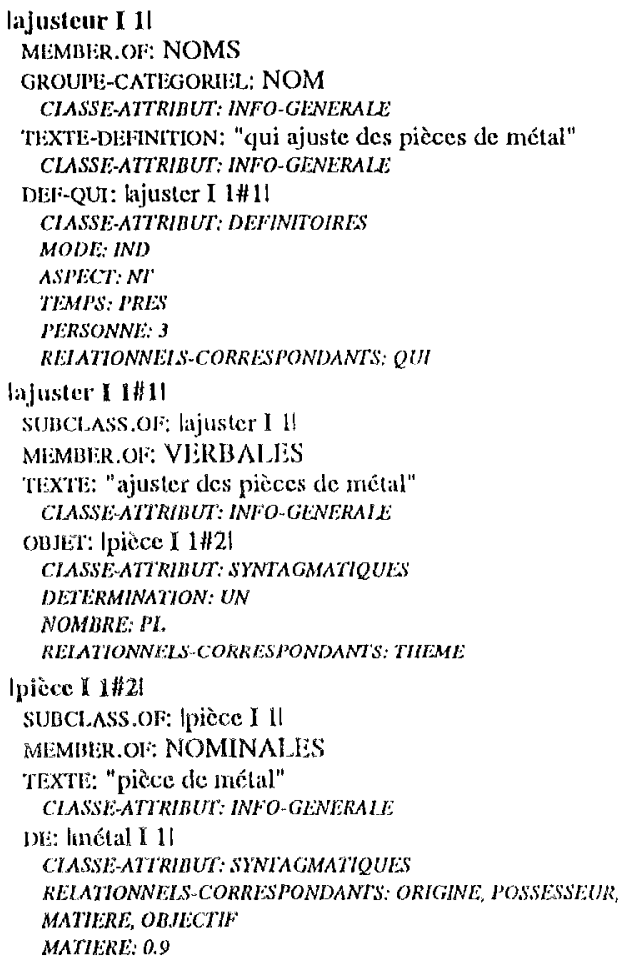

Frequently, phrasal concepts represent "unlabelled" concepts, i.c., they indecd represent concepts that do not have a significant in the language. For instance, there is not, alt least in French, a verbal concept meaning 'ajuster des pièces de métal' nor a noun Incaning 'pièce de métal'. Ifowever, this is not the case of the phrasal concepts that are linked to type concepts by means of the rclation DIIINI-P $A R$ /DLEINITYON-DI, because there, the plurasal concept is, in lact, another represcentation of the concept being defined (sec above the example of the definition of gerranium $I I$ ). In the represcatation model proposed in this work, phrasal concepts denote concepts that are typically expressed in a periphrastic way and that do not have necessarily any corresponding entry in the dictionary ${ }^{1}$.

Another interesting point related to the creation of these phrasal concepts is the maintenance of direct links between a concept and all the occurrences of this concept in the definition sentences of other concepts. It

1 This could be very interesting also, in the opinion of the authors, in a multilingual environment: if is possibite that, in ullother language, the concept equivalent to that which has been represented by the phrasal concept lyiece I 1t2l lias its own siguificant, a word that denotes it. In this case, the phrasal conecpt based representation rasy be uselul to represent the equivalence botween both concents. gives, in fact, a virtual set of usage examples that may be uscful for different functions of the final system.

\section{LNRICIIMENT PROCESSES PERHORMED ON'THE DKB.}

In this section the enrichment processes accomplished on the DKB are explaincd. Two phases are distinguished: (a) the enrichment obtained during the construction of the initial DKB, and (b), where different tasks conccrning mainly the exploitation of the properties of synonymy and taxonymy have been performed.

\subsection{Enrichment obtained during the construction of} the initial DKR.

KB-THESAURUS itself, represented - as a network - at the relational level, can be considered an curichment of the definitory level because, while the DKB was built, the following processes have been performed:

- Valtes coming from the definitory level have been promoted to the relational level.

- Values coming from the unit which represents the definiens have been transferred to the corresponding definiendum unit.

- The maintenance of the relations in both directions has becn aturomatically guarantecd.

- The concepts included in RLITERENCES have been directly related to other concepts.

- The taxonomy of concepts has becn made explicit, thus oblaining value inheritance.

\subsection{Second phase in the enrichment of the DKIs.}

Several processes have been carried out in order to infer new facts to be asserted in the $\mathrm{DKB}^{2}$. The cnrichment obtained in this phase concerns the two following aspects:

- Exploitation of the properties of the synonymy (symmetric and transitive).

- Enlargement of the concept taxonomy based on synonymy.

Another aspect that has becn considered to bo cxploited in this phase is that of disambiguation. The use of the lexical-semantic knowledge about hicrarchical relations contained in the DKB can be determinant in order to reduce the level of lexical and syntactical ambiguity ${ }^{3}$. Heuristics based on the taxonomic and synonymic knowledge obtained previously have been considered in this phase. Some of them have been designed, implemented and cvaluated in a sample of the DKB.

2 By mears of rules fired following a forward chaining strategy.

3 Lexical anbiguity comes from the defintions thernselves; syntactical ambiguity is due maisly to the amalysis process. 
6 INEERENTYAL ASPECTS: DYNAMIC DEDUCTION OF KNOWLEDGE.

Dynamic acquisition of knowledge deals with the knowledge not explicitly represented in the DKB and captured by meaus of especially conccived mechanisms which are activated when the system is to answer a question posed by the user (Arregi et al., 91). The following aspects are considered:

- Inheritance (concept taxonomy).

- Composition of lexical relations.

- I inks between concepts and relations: uscrs are allowed to use actual concepts to denote relationships (and not only primitive relations).

- Ambiguity in the DKB: treatment of remaining imcerlainty.

In the following, some aspects concening to the second point will be discussed.

In IDIS, the relationships anong the different lexical-semantic relations can be casily expressed in a declarative way. It is the way of expressing these relationships that is called the composition of lexical relations. lirom an operative point of view, this mechanism permits thc dynamic exploitation - andei the user's requests of the properties of the lexical relations in a direct manner. It is, in fact, a way of acquiring implicit knowledge from the DKB.

The declarative aspect of the mechanisn is based on the definition of triples: cach thiple expresses a relationship among differcent lexical-scmantic relations. These triples have the form $\left(R_{1} R_{2} R_{3}\right)$, where $R_{i}$ represents a lexical relation 4 . The operative effect of these declarations is the dynamic creation of transitivity rulcs based on the triples stated. The genernl form of these rules is the following:

if $X R_{1} Y$ atud $Y R_{2} Z$ then $X R_{3} Z$

When the value(s) of the attributc: $R_{3}$ are asked, a reating demon (attached to the attribute) creates the rule and lires the reasoning process wilh a backwardchaining strategy. The deduced lacts, if any, will not be asserted in the DKH, but in a temporary context.

for instance, the problem of transitivity in menonymic relations (Crusc, 86; Winsion et al., 87) can be casily expressed by stating the triple (PARTHLDIE PAR'THEDE PARTII-DE) but not stating, for inslance, (PAR'ITL-DI: MISMBRE-DF YAR CII-1)H), thus expressing that the transitivity in the sccond catse is not tous. Isxamples of other triples that have been stated in the systcm atre:

- Combination of meronynic and non-meronymic rclations:

(PARTIE-DE LOCATH' LOCATII')

(IOCATH IIYPLEONYME LOC:ATII)

(MEMBRLi-DIE UYPISRONYML MIMMBRE-D)L)
- Combination of relations derived from the definition meta-language:

(CARACITIRISTIQUE QUI-A POSSIISSION)

(OBJEC"III CH-QUI OBJLCTIF)

Explicit rules of lexical composition can be used when the general form of the triples is not valid. These rules are used following the same reasoning strategy.

Following is given the rule derived from the last triple and one instance of it. By means of this rule instance, the fact that the purpose of a géranium is the action of orner is deduced from the definitions of géranium and ornement:

$\begin{array}{ccc}\text { If } X \text { objecrn } Y \text { and } & \text {;; } & \text { the objective of } X \text { is } Y \text { (entity) } \\ Y \text { Cli-Qui } Z & \text {;; } & Y \text { "est ce qui" } Z \text { (action) }\end{array}$

then $X$ OuJECTIF $Z$; ; the objective of $X$ is $Z$ (action)

If lgéranium I $1 \mid$ ondecti lornement I 11 und

lornement I 11 CI:-QUI lorner I 1 I

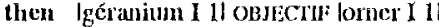

\section{" TIIE PROTOTYIE, OF IDIIS: SIZE, OF THE:} DKB.

Following some figures are given in order to slow the sixe of the prototype obtained after the initial construction of the DKY. This prototype contains an important subset of the source dictionary.

KIB-DIC:TIONNAIRI contains 2400 entrics, each one represenling ane word. KB-THLSAURUS contains 6130 conceptual units; 1738 units of these are phrasal concepts. In this KB there are 1255 anbiguous concepts. Once the initial construction phase was finished, 19691 relational arcs -interconceptual relationships- had beca established.

After the cinrichnent processes, the number of relational links have becn increnented up to $218(K)$ (10.7\%). It has been estimated that, using the mechanism of lexical composition, the number interconceptual relations could reach an increment of betwecn 5 and $10 \% 5$.

\section{CONCIUSIONS.}

A frame-based knowledge representation model has been described. This model has been wised in an Intelligent Dictionaty Melp System to represent the icxical knowledge acquired automatically from : conventional dictionary.

The chatacterisation of the different interconceptual Iexical-semantic relations is the basis for the proposed model and it has becn established as a result of the analysis process canied out on dictionary definitions.

Several entichment processes have been petfonned on the DKB - after the initial construction - in order to add new facts to it; these processes atre based on the exploitation of the propertics of lexical-semantic relations. Morcover, a mechanism for acquiring --in at dynanic way .... knowledge not explicitly iepresented

\footnotetext{
3 Considering only the set ol itiples dexdared until now.
}

A The result of the thansitivity rule that will the created will be the dedaction of values lor the $\mathrm{K}_{3}$ atuibute. The triples are tored in at facet of $\mathrm{R}_{3}$ 
in the OKH is proposed. "Whis mechanista is based on the composition of lexicat rolations.

\section{MEITLENOS:}

Alshawi, II. (1989). Analysing dictionary detinitions in B. Boguracy, $T$. Briscos eds., pp. 153-169, Computational Lcxicography for Natural Language Processing. New Y ork: I,ongman.

Amsler, R.A. (1981), A. Taxonomy for English Noun: and Verbs, Proc, lgth Annual Meeting ACL, pp, 133. 178.

Arango Gaviria, $\mathrm{O}$. (1983). Une approche pour amoreer le processus de comprehension et d"utilisaton du sens des mots en langage naturel. 'These de $3 \mathrm{cme}$ cycho (Paris VI). Publications du Groupe de Recherdio Chande linugois Picard.

Aregi $X ., X$. Artola, A. Diaz de llawad, I. Bvard, K. Saltsolat (1991). Aproximación funcional a bI $\Lambda \mathrm{C}$ : Diccionario inteligente de ayuda a la comprension, Proc. SLPLN, 11, pp. 127-138.

Artola $X_{0}, 1$. Lward. (1992). Dictionate intelligent d'aido at la comprohension, Actas IV Congreso Int.

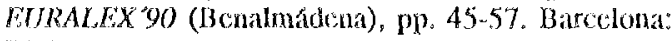
Biblograph

Artola X. (1993). "Irz"XSUA: Miztegi-sistcma urgazlo adincudunaren sorkuntea cta crakuntza / Conception d'un systène intelligent d'aide dictionnariale (SIAD) Ph.D. Thesis. UPV-1HUU.

Boguracv B., T. Briscoc cds. (1989). Computational Lexicography for Natural Language Processing. New York: Longinan.

Byrd R.J., N. Calzolari, M.S. Chodonow, J.L. Klavans, M.S. Neff, O.A. Rizk (1987). Tools and Mchoods for Computational texicography, Computational Linguistics 13, 3-4, pp. 219-240.

Calzolari, N. (1984). Machinc-teadable dictionarics, lexical data bases and the lexical system, Proc. COLING (Standford Univ.), p. 460.

Calzolari N., I. Picchi (1988). Acquisition of scmantic information from an on-line dictionary, Proc. COLING (Budapest), pp. 87-92.

Chodorow M.S., R.J. Byrd (1985). Exuacting scmantic hicrarchies from a large on-line dictionary, Proc. ACL, pp. 299-304.

Chouraqui E., I:. Godbert (1989), Representation des descriptions définics dans un réscau sćmantique, Actes 7ème Congrès Reconnaissance des Formes et Intelligence Artificielle (AICLT-INRIA, Paris), pp. 855-868.

Copestake, A. (1990). An approach to building the hicrarchical element of a lexical knowledge base from a machinc-readable dictionary, paper read at First Int. Workshop on Inheritance in NLP (Tilburg).

Cruse D.A. (1986). Lexical Semantics. Cambridge: Cambridge University Press.

van den Ilurk I., W. Meijs. The dictionary as a corpus: analyzing LDOCE's definition-language, Corpus Linguistics $I I$, pp. 99-125.
Jitkowsky K.C. (1978). Modcls of the semantic structure of dictionaries, American Journal of Computational Linguistics, MI. 81, pp. 25-74.

Makkowilu J. R. Ahlswode, M. Evens (1986). Sernantically signiticant patems in dictionary definitions, Pros. 24th Annual Meeting ACL (Now York), pp. 112,-119.

lazicnza M.'., P. Volardi (1987). A structured represcutation of word senses for somantic analysis, proc. 3rd Luropean Conforence ACt (Copenhaguen), pr. 249.25\%.

Qnillian M.R. (1968). Scmantic Mcnory in M. Minsky cd. pp. 227-370, Senantic Information Processing. Cambridge (Mass.): MrT Press.

'1surumaru II., 'T. Mitaka, S. Yoshida (1986). An atconpt to autonatic thesands constaction from an ordinary japanese langwage dictionary, Proc. COLING (Bom), pp. 445.447.

Vossen P., W. Meijs, M. den Brocder (1989). Meaning and structure in dictionary delinitions in $B$. Boguracv, T. Briscoe cds., pp. 171-19\%, Compatational lexicography for Natural language Processing. Now York: Longman.

Wilks Y., D. Iass, G. Cheng-Ming, J.I: McDonald, $\mathrm{I}$, Plats, B.M. Slator (1990). Providing Machine Tractable Dictionary Tools, Machine Tratstation, no. $5, \mathrm{pp} .99154$.

Winston M.L., R. Chatfin, D. Hermamn (198\%). A Taxonomy of Parl-Whole Relations, Cognitive Science, no. 11, pp. $417-444$. 